\title{
Elements of Digital Transformation in Dynamic Capabilities in a Brazilian Capital
}

\author{
Cláudio Márcio Campos de Mendonça ${ }^{1 *}$, António Manuel Valente de Andrade ${ }^{2}$ \\ ${ }^{1}$ Curso de Administração, Universidade Federal do Amapá, Amapá, BRAZIL \\ ${ }^{2}$ Centro de Estudos de Gestão e Economia, Católica Porto Business School, Porto, PORTUGAL
}

\section{*Corresponding Author: cmarcio@gmail.com}

Citation: Mendonça, C. M. C. and Andrade, A. M. V. (2018). Elements of Digital Transformation in Dynamic Capabilities in a Brazilian Capital. Journal of Information Systems Engineering \& Management, 3(3), 18. https://doi.org/10.20897/jisem/2654

Published: July 16, 2018

\begin{abstract}
The objective of the article was to describe the use and importance of elements of digital transformation (IoT, Big Data and Artificial Intelligence) as support for processes of dynamic capabilities in organizations of a Brazilian capital. A research is characterized as exploratory and descriptive, with a quantitative approach. 53 questionnaires were selected from business managers and IT managers. It has been identified that in the perception of business and IT managers the elements of digital transformation, even with relatively low information, mainly from IoT and IA, with a better focus on Big Data, are evaluated with importance, both nowadays, as well as in practice, up to 2025, in processes involving the dynamic capabilities of analyzing the environment (Sensing), seizing opportunities and managing as threats and transformations (Managing Threats / Transforming). With greater emphasis on Big Data in the processes of the dynamic ability to seize as opportunities.
\end{abstract}

Keywords: digital transformation, dynamic capabilities, internet of things, big data, artificial intelligence

\section{INTRODUCTION}

In recent years the economy has been evolving, at high speed, through a process of transformation, where the driving matrix is basically formed by advanced innovations in the areas: digital, material and biological. This acceleration stems from the convergence of advances in emerging technologies such as cloud computing, internet of things (IoT), robotics, artificial intelligence, autonomous vehicles, 3D printing, nanotechnology, synthetic biology, biomimetics, energy storage, among others (Preuveneers and Ilie-Zudor, 2017; Schwab, 2016).

The fourth industrial revolution, more broadly, has technologies divided into the categories: physical, digital and biological (Schwab, 2016). The digital category includes cloud computing, IoT, Artificial Intelligence and Big Data, which are part of the so-called Digital Transformation, which is a perspective of the use of information and communication technology (ICT), where it comes to act as a preponderant element in the transformation and reconfiguration of organizational elements, such as: strategy, processes, culture and structures (Hess et al., 2016).

Organizations need to be able to reconfigure themselves in the face of such a competitive market. These Dynamic Capabilities (DC) allow organizations to feel and shape opportunities and threats; seize opportunities and maintain competitiveness through the enhancement, combination, protection, reconfiguration of intangible and tangible assets.

In view of these two elements, the present article raises the question about how is the use of digital transformation technologies (IoT, Big Data and IA) in the processes of dynamic capacities in Brazilian companies? In view of the question, the following objective was defined for the present article, which is to describe the use 
and importance of elements of digital transformation (IoT, Big Data and IA) as a support to the processes of dynamic capacities in organizations of a Brazilian capital.

\section{THEORETICAL REFERENCE}

\section{Digital Transformation}

In digital transformation the perspective of information and knowledge management, the insertion of technologies that deal with the generation of data, such as The Internet of Things (IoT), as well as tools that deal with the treatment of the data (analytics - Big Data), such as: artificial intelligence, geo-analysis and cognitive computing.

\section{Internet of Things (IoT), Artificial Intelligence and Big Data}

The Internet of Things (IoT) is a technological innovation that has brought intelligence to objects, or as Zhu et al. (2015) states, is an intelligent enabler of the world, having in its structure artifacts such as the Internet and intelligent objects (Galegale et al., 2016). Radio frequency identification technologies (RFID) and sensor identification technologies will evolve further to address this new challenge in which information and communication systems are invisibly integrated into the environment around us (Gubbi et al., 2013).

In the last few years, there has clearly been an evolution of the technological artifacts that surround society in its most varied perspectives, for Makridakis (2017) one of these artifacts is AI, and he states that the impact of industrial and digital revolutions or information has substantially affected society, but there is a new revolution formed by Artificial Intelligence (AI) and that will generate a strong impact on companies and jobs. People will be able to buy goods and get services from anywhere in the world using the Internet and explore the unlimited benefits of AI as computers and robots are likely to approach human intelligence in the next 20 years. AI is a vast field of research, having several different approaches, among them: the fuzzy theory; decision trees; and neural networks. They are being used in several types of applications in different areas (Costa, 2006; Kornienko et al., 2015). And these approaches basically focus on teaching computers to think for themselves and to improvise solutions to common problems, so AI not only applies pre-programmed decisions, but rather exhibits some learning capabilities (Makridakis, 2017).

Today a challenge in the organizational environment is to create mechanisms that enables the process and analyse this large amount of data (Wolfert et al., 2017). Big Data is emerging as a relevant topic among scholars and professionals, and it is defined as a holistic approach to managing, processing, and analysing data in five dimensions, and that aims to deliver sustained value, measure performance, create skills and improve the decisionmaking process.

The Big Data dimensions are called the "5Vs", and they are: Volume - satisfaction, accessibility to data; Variety - diversity of sources and types of data; Speed - access time to information and decision making; Veracity confidence in the accuracy presented by the data; and Value - what information improves on results, the financial value used to obtain data with a good level of quality (McAfee and Brynjolfsson, 2012; Wamba et al., 2017).

\section{Dynamic Capabilities}

The theme of Dynamic Capabilities has been seen as an event in organizations and it has been arousing interest in the academic environment, as well as in the corporate environment in its most diverse segments, ranging from the strategic area to human resources management, marketing, innovation, entrepreneurship and information and knowledge management.

In the view of dynamic capacities acting as routines and processes, (D. J. Teece, 2014) affirms the necessity of the existence of some capacities that are related to processes, which is in the same line of thought as (Eisenhardt and Martin, 2000), and that can: act in analysing the external environment in the which the company is inserted (sensing); seize the chances / opportunities (seizing); and manage threats and transformations which have arisen from organizational changes (managing threats/ transforming).

In short, the dynamic capacity is the grouping of skills, behaviours and organizational capacities, as well as processes and routines that lead the company to differentiate itself in the competitive market ahead of its competitors.

\section{METHODOLOGY}

The present study is characterized as exploratory and descriptive, because it seeks to identify possible relations and differences between a set of variables and without necessarily worrying about the question of causality. Regarding the nature of the study and approach to the problem, a quantitative study was done using the descriptive 
Table 1. Current Importance, Performance, Future Importance of Dynamic Sensing Capacity

\begin{tabular}{llccc}
\hline Technology & Dimension & Average & Median & Mode \\
\hline \multirow{2}{*}{ IoT } & Current Importance & 3,79 & 4,00 & 1 \\
\cline { 2 - 5 } & Performance & 2,11 & 2,00 & 1 \\
\cline { 2 - 5 } Bmportance (future perspective) & 5,02 & 5,00 & 6 \\
\hline \multirow{2}{*}{ Big Data } & Current Importance & 4,42 & 5,00 & 3 \\
\cline { 2 - 5 } & Performance & 3,58 & 4,00 & 4 \\
\cline { 2 - 5 } & Importance (future perspective) & 5,00 & 5,00 & 6 \\
\hline & Current Importance & 3,04 & 3,00 & 2 \\
\cline { 2 - 5 } & Performance & 1,83 & 1,00 & 7 \\
\hline
\end{tabular}

Source: Research Data (2017)

survey study method. As for the moment of collection of the study, the cross-sectional study was used in a single moment in order to describe and analyse the state of the variables at a given moment.

For the quantitative study the sampling used was non-probabilistic and its elements were selected according to the convenience of the researcher. For the application of the questionnaires with closed and open questions, an electronic instrument was used to apply the questionnaires. The link was sent to professionals from the IT and Administration areas of Rio Grande do Norte by email and it was also forwarded to closed groups of professionals from both areas on Facebook. They were sent to approximately 350 professionals. A total of 72 questionnaires were answered. After the analysis and exclusion of incompletely answered questionnaires and questionnaires answered by people who were not business or IT managers, 53 questionnaires were valid, only those respondents who said that they were IT or business managers.

A pilot test of the questionnaire was sent to two $\mathrm{PhD}$ students in management with knowledge in the area of technology and innovation. The questionnaire was also submitted for the evaluation of two persons with a doctorate degree with experience in quantitative instruments. After the suggestions, the considerations were accepted and implemented in the research instrument. The Cronbach's alpha obtained was relatively high for the questions involving the dynamic capacities, being 0.925 for the 9 questions with Likert-type scale. When separated by categories, the value of 0.925 was obtained for questions related to IoT, 0.945 for Big Data and 0.878 for Artificial Intelligence.

\section{ANALYSIS AND INTERPRETATION OF RESULTS}

\section{Respondents Profile}

In descriptive statistics, there was a greater participation of respondents from large companies $(50.9 \%)$, which added to the percentage of medium-sized companies $(17 \%)$, represent the majority of respondents with $67.9 \%$. Microenterprises represented $17 \%$, and small companies with the lowest percentage of $15.1 \%$. Of these companies, $67.9 \%$ are nationals and $32.1 \%$ are non-multinationals. Regarding the type of delivery, the company makes to its customer, the percentage of 39.6\% was identified for "Product and Service", followed only by "Service" with 34\% and by "Product" with 14\%. This represents in a similar way the characteristics of the Natal-RN region. The researchers chose to select only the questionnaires answered by managers, be they business or IT, the results indicated a greater predominance of business managers with $62.3 \%$, while IT managers were $37.7 \%$.

\section{Matrix Importance (current and future) x Performance}

\section{Dynamic Capacity Sensing (To Analyse the Environment)}

According to Teece (2007) the dynamic capacity Sensing, which has processes that allow for the analysis of the external environment in which the organization is inserted; processes that allow directing internal P \& D work; seek suppliers to complement the organization's innovations; seek scientific and technological developments outside the firm; and recognize target market segments by changing customer needs and generating customerdriven innovations.

In Table 1 it is demonstrated through the analysis of the averages, medians and modes obtained through Likerttype scale analysis, that among the three technologies (IoT, Big Data and IA), Big Data has better performance (median 4 and average 3,58), followed by IoT (median 2 and average 2.11), and finally the use of Artificial Intelligence, with a still incipient performance or almost non-use (median 1 and average 1.83). The data also suggest that the 3 technologies are little used for these types of processes of detection of elements of the external environment.

According to Dobre and Xhafa (2014), the technologies that involve Big Data are more accessible to organizations, which may be contributing to better performance among the 3 technologies surveyed. In addition, 
Table 2. Current Importance, Performance, Future Importance of Dynamic Seizing Capacity

\begin{tabular}{llccc}
\hline Technology & Dimension & Average & Median & Mode \\
\hline \multirow{2}{*}{ IoT } & Current Importance & 3,81 & 4,00 & 5 \\
\cline { 2 - 5 } & Performance & 2,53 & 2,00 & 1 \\
\cline { 2 - 5 } Big Data & Current Importance & 4,58 & 5,00 & 5 \\
\hline \multirow{2}{*}{ Artificial intelligence } & Performance & 4,47 & 5,00 & 5 \\
\cline { 2 - 5 } & Importance (future perspective) & 3,72 & 4,00 & 4 \\
\cline { 2 - 5 } & Purrent Importance & 5,21 & 6,00 & 7 \\
\cline { 2 - 5 } & Importance (future perspective) & 3,21 & 3,00 & 3 \\
\hline
\end{tabular}

Source: Research Data (2017)

Big Data favours the capture of external data and information, which is the main focus of Sensing's dynamic capability. As an example, it occurs with social networks where it allows very economical analyses and opinions of the external environment in a faster way (Venkatram and Geetha, 2017). Regarding the current importance, it was observed that the managers perceive the three technologies as important today, even those that are underperforming. And that the prospect of future importance has a considerable increase, suggesting that respondents believe that IoT, Big Data and AI will be more important in processes of the dynamic capacity of detecting the external environment, again with the highest percentages for the Big Data technology. Another issue that may indicate the greatest use and importance (current and future) of Big Data is that this technology has a strong relationship with what Teece (2007) argues with regard to the processes of the dynamic capacity to analyse the environment (sensing), where to succeed, organizations need to interpret the available information in whatever form it appears, whether through graphics, images, news of scientific and technological advances, or the anguish expressed by a frustrated customer. It is necessary to accumulate and then filter information from professional and social contacts to create a conjecture or hypothesis about the likely evolution of technologies, customer needs, and market responses. This task involves monitoring internal and external technological developments and evaluating customer needs, expressed and latent, as well as learning, interpretation and creative activity (Dobre and Xhafa, 2014). Such detection (sensing) is essential for the company to sustain itself over the long term as customers, competitors and technologies change (Teece et al., 2016).

\section{Dynamic Seizing Capacity (Seize the Opportunities)}

Processes focused on customer solutions, selection of organizational boundaries, selection of decision-making protocols and those related to the building of employee loyalty and commitment, are part of Seizing's dynamic capabilities that enable the mobilization of resources to meet the needs and make the most of the opportunities (Teece et al., 2016; Teece, 2007).

Table 2 identifies higher percentages in the 3 technologies when compared to the dynamic sensing capabilities. Again, there is a predominance in the performance of Big Data technology in relation to IoT and IA, with averages of 3.72, 2.53 and 1.72, and medians of 4, 2 and 1, respectively.

These higher averages and medians in the performance of the 3 technologies for the capabilities of exploring opportunities detected in the internal and external environment of the organization, suggest the greater use of technologies for these processes, and this is in agreement with (Teece, 2007), who informs that in order to address the opportunities (Seizing), there must be maintenance and improvement of technological skills and complementary resources, and then when the opportunity is mature, investing heavily in the most probable technologies and designs to achieve greater acceptance of the Marketplace. For the dynamic capacity to seize opportunities, it was observed that the performance and importance (current and future) of the use of Big Data was superior to the other dynamic capacities and technologies. This fact may be occurring because this dynamic capacity has a strong relation with the decision-making process through the definition and use of decision protocols. According to Erevelles et al. (2016); Venkatram and Geetha (2017); Vieira et al. (2017), the justification for using Big Data technology is due to its use in the the decision making process, where better decisions are seized, in order to increase the likelihood of success and minimization of risk.

\section{Dynamic Capacity Threats/Transforming (Manage Threats and Opportunities)}

According to Meirelles and Camargo (2014) and Teece (2007) there is a third capacity that serves as a foundation for dynamic capabilities, which is called Managing Threats / Transforming, and its composition involves processes that address issues of decentralization and decomposition of the organizational structure; the specialization of assets of the organization; and aspects related to learning, knowledge sharing, and governance.

As in the Sensing and Seizing capabilities, it was observed that the performance of the Big Data technology was superior to IoT and AI. It was observed that when comparing the average of Io'T technology performance in this dynamic capacity with the others, that its performance was better, as shown in Table 3. It is also worth noting 
Table 3. Current importance, performance, future importance of dynamic capacity Managing Threats/Transforming

\begin{tabular}{|c|c|c|c|c|}
\hline Technology & Dimension & Average & Median & Mode \\
\hline \multirow{3}{*}{ IoT } & Current Importance & 3,60 & 4,00 & 1 \\
\hline & Performance & 2,79 & 2,00 & 1 \\
\hline & Importance (future perspective) & 4,55 & 5,00 & 6 \\
\hline \multirow{3}{*}{ Big Data } & Current Importance & 4,47 & 5,00 & 5 \\
\hline & Performance & 3,34 & 3,00 & 1 \\
\hline & Importance (future perspective) & 5,43 & 6,00 & 7 \\
\hline \multirow{3}{*}{ Artificial intelligence } & Current Importance & 3,45 & 3,00 & 2 \\
\hline & Performance & 1,81 & 1,00 & 1 \\
\hline & Importance (future perspective) & 4,72 & 5,00 & 7 \\
\hline
\end{tabular}

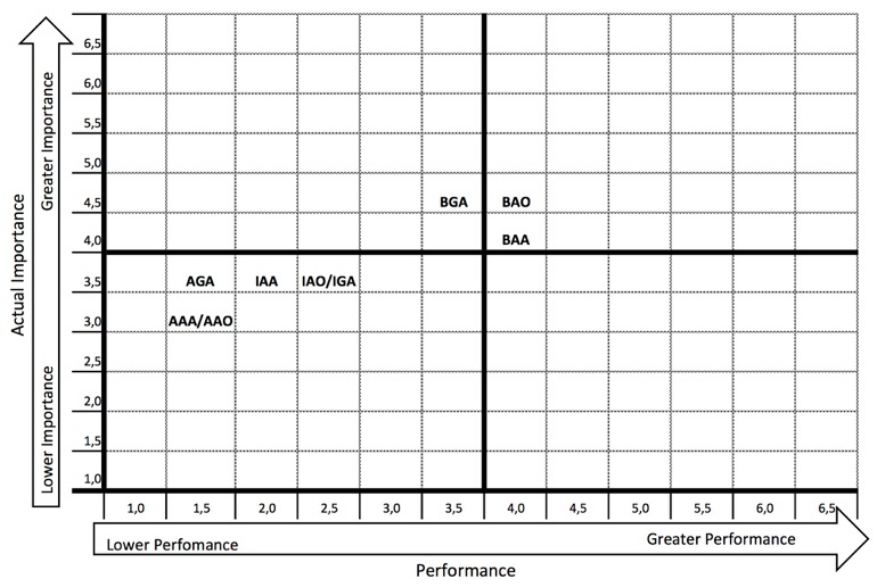

Figure 1. Matrix current importance x Current Performance

the high percentage of respondents that there is no performance of the AI for this dynamic capacity (50.9\%). This suggests still the immaturity of the use of artificial intelligence in the companies surveyed.

In relation to the current importance and importance in the future perspective, it was detected in both a less importance attributed to Io'T technology, when compared with the other dynamic capacities. Perhaps this is due to the fact that the processes that involve this dynamic capacity are related to decision making (centralization or decentralization), with cross reference of information of different assets, with learning, sharing and integration of knowledge (Meirelles and Camargo, 2014). These characteristics are more related to analyses, which may suggest greater use of Big Data solutions and later with AI. This pattern, precisely observed, where in relation to Big Data and AI, there could be seen an increase in the current and future importance of the Sensing and Seizing capabilities. For Gunasekaran et al. (2017) Big Data acts positively on information sharing, integration and transformation in the chain in which the organization is a part, as well as organizational performance.

\section{Matrix Three-dimensional Importance}

It was decided to divide the matrix of importance and performance into two parts. The first using the current importance versus actual observed performance. And the second, using the Importance in the future perspective versus current performance observed. Four quadrants were defined in each graph, which were divided as follows: from 1.0 to 3.9 (average) Lower Importance / Lower Performance and from 4.0 to 7.0 (average) Higher Importance / Higher Performance. For better understanding, here is the legend:

IAA - Io'T with the DC of analysing the environment (Sensing); IAO - IoT with the DC of seizing opportunities (Seizing); IGA - IoT with the DC of managing threats (Managing Threats/Transforming); BAA - Big Data with the DC of analysing the environment (Sensing); BAO - Big Data with the DC of seizing opportunities (Seizing); BGA - Big Data Io'T with the DC of managing threats (Managing Threats/Transforming); AAA -Artificial Intelligence with the DC of analysing the environment (Sensing); AAO -Artificial Intelligence with the DC of seizing opportunities (Seizing); AGA -Artificial Intelligence with the DC of managing threats (Managing Threats/Transforming).

When analysing Figure 1, showing Current Importance versus Current Performance, the IoT and Artificial Intelligence technologies for the 3 dynamic capacities are observed in the quadrant of less importance and lower performance. On the other hand, Big Data is seen as a technology with higher performance in dynamic capabilities.

When analysed with the importance, it is observed that among the respondents IoT and Artificial Intelligence technologies are in the quadrant of lower current importance, that is, these two services, on top of having a lower performance, are seen with less importance for the three dynamic capabilities (to analyse the environment, seize 


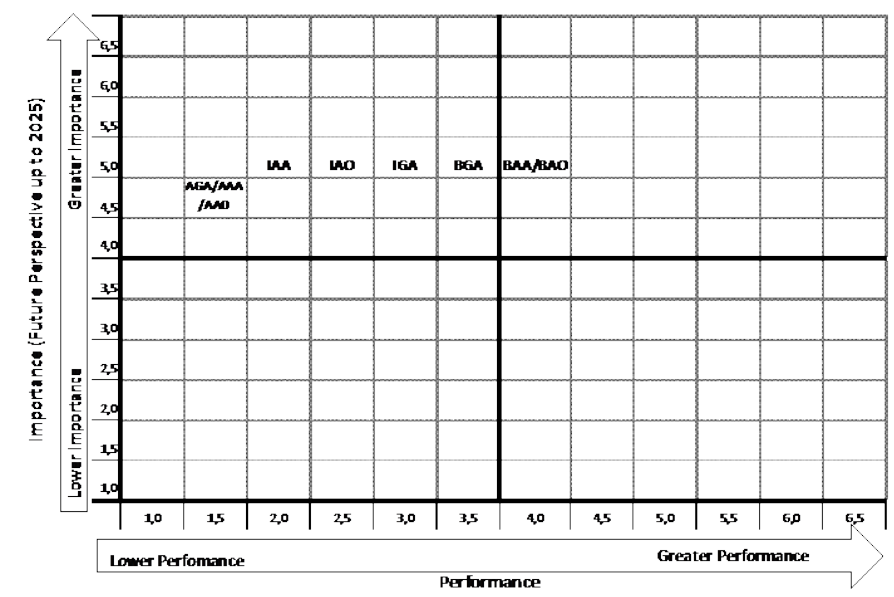

Figure 2. Matrix Importance Future Perspective (2025) x Current Performance

the opportunity and manage threats/opportunities). It is also suggested that Artificial Intelligence has the lowest performance among the 3 technologies. Probably the low performance is related to the low use, due precisely to the issue of maturity of the technology itself, as it is stated by Makridakis (2017) who says that the revolution provided by AI happens in the space of the next 20 years, and that there are two relevant aspects to deal with these AI challenges, the first is that the hazards are well understood, and the second, is that there is a lot of time to debate the problems and take wise actions to deal with them effectively.

For two of the dynamic capabilities, to analyse the environment (Sensing) and seize the opportunities (Seizing), Big Data technology fitted into the quadrant of greater performance and greater importance. This is probably due to the fact that managers already have greater knowledge of this technology, because it is the most used and experienced. Managers have probably realized that as data become larger, more complex, and more inexplicable, there is a need to assist humans' mental capacity to analyse/filter out this large amount of information and knowledge (Erevelles et al., 2016). In addition, according to McAfee and Brynjolfsson (2012), the challenge is to intelligently collect information on this large mass of data, which has more volume and variety with higher speed.

Figure 2, which contains the Importance (future perspective up to 2025) versus the Current performance, shows a greater importance attributed to the 3 technologies in the 3 dynamic capacities, with a greater emphasis on the increase in the importance of IoT and Big Data. Even with this increase in future importance, in managers' perceptions, it is worth observing the need for organizations to take care of issues involving individual privacy, as Adams (2017) argues, protecting personal data in the era of Big Data and IoT requires a multifaceted approach and greater control from the data's owner.

Artificial intelligence migrated from the quadrant of lower importance to greater importance. This suggests that business and IT managers have a perspective of more relevance of these 3 technologies in their organizations within 7 years (2025).

It is also observed that, even with lower current performance, the technologies are perceived as more important (current or future) in the performance of the processes of the dynamic capacities addressed in the study. This may be due to the fact that organizations' needs in competitive environments need to be reconfigured more quickly. With greater emphasis on $\mathrm{BAO}$ - Big Data in the processes of the dynamic capabilities of seizing the Opportunities and BAA - Big Data in the processes of the dynamic capabilities of Analysing the Environment.

\section{FINAL CONSIDERATIONS}

In the process of digital transformation, as stated by Matt et al. (2015), in recent years companies in almost every industry have undertaken various initiatives to explore new digital technologies and explore their benefits. Consequently, there are transformations of important business operations and it affects products and processes, as well as organizational structures and management concepts.

According to the study and its goal, organizations, mostly large and medium-sized enterprises (67.9\%), from the state of Rio Grande do Norte, in the perception of business and IT managers, technologies (IoT, Big Data and $\mathrm{AI})$ of the so-called digital transformation are still in an early stage process of use.

In terms of performance and use, it was observed that the Big Data technology was highlighted in relation to IoT and IA, in the 3 dynamic capacities: to analyse the environment (sensing); seizing opportunities (seizing) and managing threats (managing threats/transforming).

The best performance observed among the dynamic capabilities of Big Data technology was related to the processes of the dynamic capacity of seizing opportunities (seizing), which have to do with issues that involve the 
search for solutions for clients, decision-making protocols and routines to search and build a greater loyalty and commitment of the employees, which according to Teece (2007), considerably increases the performance in the organization. The result suggests that this may be due to Big Data's characteristics of allowing collection and analysis of a large body of data and information, already generated and shared by organizations, from a variety of sources (structured, semi-structured, and unstructured). In addition to the amount of solutions on the market that involve this technology.

Still with respect to performance, the technology of Artificial Intelligence is the one that obtained lower performance. AI is still seen as having low maturity and use by local companies. In any case, this may be due to the characteristics of the companies, mostly focused on providing services, where there are not many solutions implemented and commercially matured, yet. The performance of IoT in the 3 dynamic capacities is also still incipient, but it has surpassed the performance of Artificial Intelligence.

With regard to current and future importance (perspective up to 2025), a linearity was observed in relation to performance. The higher the performance, the greater the current and future importance attributed. In any case, it is worth noting that Artificial Intelligence technology, although it has low performance and a minor perceived current importance, was the technology that obtained the greatest gap between the current importance and importance in the future perspective, and this happened in the 3 dynamic capacities. The data suggest that while currently underused, IT and business managers believe that the importance of using artificial intelligence technology will increase over the next 7 years.

Thus, it was identified that in the perception of business and IT managers the elements of digital transformation, even with the relatively low use, mainly of IoT and AI, with a better emphasis on Big Data, are seen as important, both currently and in the perspective up to 2025, in processes that involve the dynamic capabilities of analysing the environment (Sensing), seizing opportunities (seizing) and managing threats and transformations (managing threats/transforming).

\section{REFERENCES}

Adams, M. (2017). Big Data and Individual Privacy in the Age of the Internet of Things, 7(4), 12-24.

Costa, H. R. N. (2006). Aplicaşão de técnicas de inteligência artificial em processos de fabricaşão de vidro. Universidade de São Paulo - USP. https://doi.org/10.11606/T.3.2006.tde-09032007-171929

Dobre, C. and Xhafa, F. (2014). Intelligent services for Big data science. Future Generation Computer Systems, 37, $267-$ 281. https://doi.org/10.1016/j.future.2013.07.014

Eisenhardt, K. M. and Martin, J. A. (2000). Dynamic capabilities: what are they? Strategic Management Journal, $21(10$ 11), 1105-1121. https://doi.org/10.1002/1097-0266(200010/11)21:10/11<1105::AID-SMJ133>3.0.CO;2-E

Erevelles, S., Fukawa, N. and Swayne, L. (2016). Big Data consumer analytics and the transformation of marketing. Journal of Business Research, 69(2), 897-904. https://doi.org/10.1016/j.jbusres.2015.07.001

Galegale, G. P., Siqueira, E., Souza, C. A. de and Silva, C. B. H. (2016). Internet das Coisas aplicada a negócios: Um estudo bibliométrico. Journal of Information Systems and Technology Management, 13(3), 423-438. https://doi.org/10.4301/S1807-17752016000300004

Gubbi, J., Buyya, R., Marusic, S. and Palaniswami, M. (2013). Internet of Things (IoT): A vision, architectural elements, and future directions. Future Generation Computer Systems, 29(7), 1645-1660. https://doi.org/10.1016/j.future.2013.01.010

Gunasekaran, A., Papadopoulos, T., Dubey, R., Wamba, S. F., Childe, S. J., Hazen, B. and Akter, S. (2017). Big data and predictive analytics for supply chain and organizational performance. Journal of Business Research, 70, 308-317. https:/ / doi.org/10.1016/j.jbusres.2016.08.004

Hess, T., Benlian, A., Matt, C. and Wiesböck, F. (2016). Options for Formulating a Digital Transformation Strategy. MIS Quarterly Executive, 15(2), 123-139.

Kornienko, A. A., Kornienko, A. V., Fofanov, O. B. and Chubik, M. P. (2015). Knowledge in Artificial Intelligence Systems: Searching the Strategies for Application. Procedia - Social and Behavioral Sciences, 166, 589-594. https://doi.org/10.1016/j.sbspro.2014.12.578

Makridakis, S. (2017). The Forthcoming Artificial Intelligence (AI) Revolution: Its Impact on Society and Firms, 90, 46-60. https:// doi.org/10.1016/j.futures.2017.03.006

Matt, C., Hess, T. and Benlian, A. (2015). Digital Transformation Strategies. Business and Information Systems Engineering, 57(5), 339-343. https://doi.org/10.1007/s12599-015-0401-5

McAfee, A. and Brynjolfsson, E. (2012). Big Data : The Management Revolution. Har, (OctOBeR).

Meirelles, D. S. e and Camargo, Á. A. B. (2014). Capacidades Dinâmicas: O Que São e Como Identificá-las? Dynamic Capabilities: What Are They and How to Identify Them? Revista de Administração Contemporânea, 18(Dezembro), 41-64. https:// doi.org/10.1590/1982-7849rac20141289 
Preuveneers, D. and Ilie-Zudor, E. (2017). Introduction to the thematic issue on Intelligent systems, applications and environments for the industry of the future. Journal of Ambient Intelligence and Smart Environments, 9(3), 285286. https://doi.org/10.3233/AIS-170431

Schwab, K. (2016). A Quarta Revolução Industrial (Edipro). São Paulo. Available at: http://www.edipro.com.br/produto/a-quarta-revolucao-industrial/

Teece, D. J. (2007). Explicating Dynamic Capabilities: The Nature and Microfoundations of (Sustainable) Enterprise Performance. Strategic Management Journal, 1319-1350. https://doi.org/10.1002/smj.640

Teece, D. J. (2014). The Foundations of Enterprise Performance: Dynamic and Ordinary Capabilities in an (Economic) Theory of Firms. Academy of Management Perspectives, 28(4), 328-352. https://doi.org/10.5465/amp.2013.0116

Teece, D., Peteraf, M. and Leih, S. (2016). Dynamic Capabilities and Organizational Agility: RISK, UNCERTAINTY, AND STRATEGY IN THE INNOVATION ECONOMY. California Management review, 58(4). https://doi.org/10.1525/cmr.2016.58.4.13

Venkatram, K. and Geetha, M. A. (2017). Review on Big Data; Analytics - Concepts, Philosophy, Process and Applications. Cybernetics and Information Technologies, 17(2), 3-27. https://doi.org/10.1515/cait-2017-0013

Vieira, V., Pedrosa, I. and Soares, B. H. (2017). Big data \&amp; analytics: An approach using audit experts' interviews. In 2017 12th Iberian Conference on Information Systems and Technologies (CISTI) (p. 1-6). IEEE. https://doi.org/10.23919/CISTI.2017.7976069

Wamba, S. F., Gunasekaran, A., Akter, S., Ren, S. J., Dubey, R. and Childe, S. J. (2017). Big data analytics and firm performance: Effects of dynamic capabilities. Journal of Business Research, 70, 356-365. https://doi.org/10.1016/j.jbusres.2016.08.009

Wolfert, S., Ge, L., Verdouw, C. and Bogaardt, M. J. (2017). Big Data in Smart Farming? A review. Agricultural Systems, 153, 69-80. https://doi.org/10.1016/j.agsy.2017.01.023

Zhu, C., Leung, V. C. M., Shu, L. and Ngai, E. C. H. (2015). Green Internet of Things for Smart World. IEEE Access, 3, 2151-2162. https://doi.org/10.1109/ACCESS.2015.2497312 